\title{
LA VULNERABILIDAD FUNDANDO LA ÉTICA DE LA SOLIDARIDAD Y LA JUSTICIA
}

\author{
VULNERABILITY FOUNDING THE ETHICS OF SOLIDARITY AND \\ JUSTICE
}

Marta Palacio

"El Yo, de pie a cabeza, hasta la médula de los huesos, es vulnerabilidad"

(LEVINAS 2001, p. 123)

Recibido: $19 / 12 / 2014$

Aceptado: 27/02/2015

\section{RESUMEN}

El texto reconstruye hermenéuticamente el concepto de vulnerabilidad de la filosofía de Emmanuel Levinas tal como aparece en su obra madura. Analiza el giro radical que la filosofía levinasiana comporta para la tradición ética y política al establecer como fundamento de la justicia y la solidaridad a la vulnerabilidad del sujeto. Finalmente, el artículo valora el aporte levinasiano ante la demanda contemporánea de fundamentos del obrar humano para establecer argumentativamente lógicas de justicia y solidaridad frente a la creciente vulnerabilidad urbana.

PALABRAS ClavE: Vulnerabilidad, Subjetividad ética, Levinas, Solidaridad, Justicia

\begin{abstract}
The text make a hermeneutical reconstruction of the concept of vulnerability in the philosophy of Emmanuel Levinas as displayed in his mature work. Analyzes the radical shift that Levinas's philosophy entails for ethical and political tradition as the basis for establishing justice and solidarity to the vulnerability of the subject. Finally, the paper assesses the contribution to the contemporary Levinas demand fundamentals of human action to establish argumentatively logic of justice and solidarity in the growing urban vulnerability.
\end{abstract}

KEYWORDS: Vulnerability, Ethical Subjectivity, Levinas, Solidarity, Justice 
Estas reflexiones filosóficas son fruto del diálogo de dos géneros discursivos, uno, descriptivo y observacional, que da cuenta de la creciente e innegable realidad de la vulnerabilidad urbana; y el otro discurso, el propiamente filosófico de tipo argumentativo-crítico, que intenta desarrollar una reflexión ética sobre la razón de la solidaridad y la justicia frente a la vulnerabilidad, habilitando así una vía de comprensión sobre esta realidad que nos sobrecoge y espanta.

Este es un ensayo del pensar interdisciplinario sobre la cuestión de la vulnerabilidad urbana que nos deja perplejos y nos desafía a la comprensión del fenómeno: parte de la sociología o análisis cultural, que da cuenta de los hechos observables, a la filosofía que los reflexiona críticamente, y de ésta a aquella, para que en una circularidad virtuosa se evite la generalización abstracta que nada dice sobre la vida concreta. ${ }^{2}$

\section{LA CUESTIÓN DE LA VULNERABILIDAD URBANA INTERPELADA POR LA FILOSOFÍA LEVINASIANA DE LA VULNERABILIDAD}

Entre los problemas más complejos que tenemos que afrontar las mujeres y hombres de este siglo se halla la cuestión de la "convivencia" en sociedades "de-socializadas" en las que sus individuos experimentan una "creciente vulnerabilidad urbana", que pareciera no tener reparo en los descompuestos tejidos sociales del modelo republicano y democrático del Estado-nación moderno. ${ }^{3}$ En este proceso de resquebrajamiento del vínculo social y político

\footnotetext{
${ }^{1}$ En este sentido, la inquietud filosófica que guía a este trabajo lo inscribe junto con el de otros autores y comentaristas levinasianos preocupados por la renovación de la racionalidad práctica posmetafísica. Ver: (BELLO 1994, 149-182; SCANNONE 2013, 233-246; BERNASCONI 2004, 43$58)$.

${ }^{2} \mathrm{El}$ intento de comprender una realidad atroz que nos golpea, como modo de filosofar, fue "inaugurado" por Hannah Arendt a partir de la publicación The Origins of the Totalitarianism (1948). En el Prólogo de la reedición de 1967, expresa Arendt: "Comprender... significa, más bien, examinar y soportar conscientemente la carga que los acontecimientos han colocado sobre nosotros- ni negar su existencia ni someterse mansamente a su peso como si todo lo que realmente ha sucedido no pudiera haber sucedido de otra manera. La comprensión, en suma es un enfrentamiento impremeditado, atento y resistente, con la realidad." (ARENDT 2006, p. 33). El subrayado es nuestro.

${ }^{3}$ En la ciudad de Córdoba (Argentina) tuvimos la experiencia de esta flagrante ausencia de contrato social durante los saqueos y la violencia ciudadana tras el "acuartelamiento" de la
} 
han incidido varios elementos: la transformación de la sociedad civil por los bruscos y vertiginosos cambios tecnológicos, la masificación de la vida urbana, los nuevos modos de producción y consumo, las migraciones, los intensos intercambios simbólicos y la emergencia de las diversidades culturales en el contexto de la globalización.

La extrema "vulnerabilidad" que se observa en las vidas humanas y los lazos sociales se encuentra sumergida en la lógica hegemónica del mercado, que va eliminando a su voraz paso tanto prácticas, tradiciones y valores sociales como formas de vida propias de la modernidad. Vulnerabilidad que se vuelve particularmente palpable en los grandes conglomerados urbanos y las megaciudades donde la "precariedad" de la vida se halla expuesta en toda su desnudez. ${ }^{4}$

Estamos insertos/as dentro de una particular época histórica: la de un "cambio de paradigma" de nuestras representaciones de la vida social y personal, como plantea con agudeza Alain Touraine (TOURAINE 2006). Aunque, claro está, la transmutación no es homogénea ni lineal ni acontece a un ritmo constante en las diversas sociedades que va engullendo en su paso transformador. Los cambios se hallan segmentariamente distribuidos en la geografía mundial, concentrándose principalmente el vector de mayor mutación en aquellas regiones en que la tecnología y la economía de consumo han llegado a ser patrones dominantes de la vida societaria como lo son las grandes urbes del Primer Mundo: Tokio y Nueva York, y las megapolis latinoamericanas: México DF, Buenos Aires, Lima, Río de Janeiro, entre otras; megaciudades que presentan rasgos prominentes de dualización de sus habitantes por la existencia en su seno de grandes bolsones de pobreza y marginalidad.

La desoladora sensación de disolución del contrato social y la confusión por la pérdida de las brújulas orientadoras de la vida en común se hallan a flor de piel entre los sujetos de nuestra precipitada era de la globalización. El temor ante la pérdida de la imagen confiada que nos ofrecía el pasado bajo el mito del progreso de las sociedades y la desconfianza ante el espectro de un futuro oscuro e incierto nos pueden encerrar en un individualismo auto-referenciado e

Policía de la Provincia los días 3 y 4 de diciembre de 2013. Para mayores detalles ver nota publicada en el diario La Nación del 4/12/13.

${ }^{4}$ La cuestión de la precariedad de la vida ha sido objeto de numerosas tematizaciones filosóficas contemporáneas que han recogido las tesis levinasianas sobre la alteridad y la responsabilidad por el otro. Véase ButLer (2006); DERRIDA y ROUDINESCO (2003). 
indiferente ante la vulnerabilidad de los otros, ahondando así aún más el proceso de desligamiento social o, lo que es peor, naturalizando la violencia como modo habitual de convivencia; precarizando y vulnerando aún más la vida humana, tal como se observa actualmente en varias regiones de Latinoamérica que en la última década ha experimentado un preocupante crecimiento en sus indicadores de "violencia urbana" (Informe Regional de Desarrollo Humano ONU 2013-2014).

Desde el punto de vista sociológico, cuando se habla de "vulnerabilidad urbana" de los sujetos sociales se entiende a un proceso gradual de exclusión y marginación de los derechos sociales, económicos y políticos que se ejercen en la ciudad. Este proceso de exclusión social se produce como una "acumulación de desventajas" que horada la relación individuo-sociedad y comienza a partir de un riesgo o una desventaja inicial que padece la persona, la que se va incrementando e intensificando con otros riesgos hasta producir su exclusión definitiva del entramado social (SARAVí 2006). Los fenómenos de desnutrición, desescolarización, desempleo, explotación laboral, abandono, delincuencia, migración ilegal, riesgo de ser víctimas del narcotráfico, prostitución y trata de personas, pueden considerarse epifenómenos del proceso de vulnerabilidad urbana. Este conduce progresivamente a los sujetos a la desvinculación social y concluye en un estadio de anulación permanente de todo derecho, e incluso del "reconocimiento de humanidad" y del "derecho a tener derechos" (Arendt 385-427) -para decirlo en términos arendtianos- hasta que sus muertes ya no le importan a nadie.

Si actualmente más de la mitad de la población mundial vive en ciudades cuyo futuro se está configurando ahora, (Eckholt) la apuesta de los intelectuales y de la política es pensar y diseñar lógicas cuyas reglas de juego puedan revertir la situación de exclusión de inicio, riesgo o desventaja histórica, mediante acciones positivas de justicia y solidaridad hacia las personas en situación de vulnerabilidad urbana que serán ejecutadas por diversos organismos de la ciudadanía e instituciones públicas.

La tarea propia de la filosofía en este contexto es repensar las preguntas sobre la fundamentación del obrar humano y sobre la obligación ante los otros, puesto que la creciente vulnerabilidad urbana como proceso histórico colectivo nos involucra y afecta a todos. Quizás así, al menos, el reiterado esfuerzo del pensamiento logre conjurar la amenaza de deshumanización que nos acosa y nos paraliza como al ángel espantado de la historia que relata Walter Benjamin (BENJAMIN 2007)

Análisis. Revista de Investigación filosófica, Vol. 2, n. 1 (2015): 29-47 
¿Por qué debo respetar al otro? ¿Por qué debo ayudarlo? ¿Podremos convivir humanamente? ¿Bajo qué normas y pautas hacerlo? ¿En qué tipo de organización política? Si la libertad ha sido desenmascarada por la crítica filosófica como "voluntad de poder" (Nietzsche) o arbitrariedad y "alergia al otro" (Levinas) ¿Sobre qué concepto o categoría podremos fundar la justicia y la solidaridad? ¿Por qué estamos obligados ante los otros? ¿La responsabilidad por los otros que sufren en nuestras ciudades queda librada a merced a la disposición del Estado y sus leyes o a la libre elección de cada ciudadano/a?

La cuestión de la convivencia pacífica presupone el análisis y la reflexión filosófica sobre la "subjetividad ética" y el fundamento de la obligación moral del respeto y la respuesta que debemos ante la vulnerabilidad de los otros. ${ }^{5} \mathrm{La}$ pregunta filosófica nos lleva a replantearnos la responsabilidad que nos incumbe como intelectuales, particularmente sobre los crecientes procesos de vulnerabilidad urbana en nuestra región latinoamericana.

La tematización de Emmanuel Levinas sobre "la vulnerabilidad del sujeto" es una vía racional que nos permite invertir los términos de la argumentación ética clásica sobre el fundamento de la solidaridad y la justicia al ubicarnos en otro espacio teórico, del todo diferente a los habituales de la tradición del pensamiento ético y político.

En efecto, Levinas plantea un giro radical respecto a la tradición filosófica al colocar como fundamento de la solidaridad y la justicia la "vulnerabilidad" del sujeto. También opera un desplazamiento del concepto sociológico, que circunscribe la vulnerabilidad a la vida "de los otros"- los vulnerables por procesos de exclusión social- al argumentar que el soporte o "anudamiento ético" de la responsabilidad por el Otro yace en la "propia vulnerabilidad del sujeto" afectado por la "vulnerabilidad del rostro desnudo del otro". ${ }^{6}$ Debido a esta vulnerabilidad del sujeto apelada por la vulnerabilidad del otro se constituye una nueva subjetividad, el "Otro-en-el-Mismo" (LevinAs 1987, p. 136), entendida como responsabilidad y donación "a pesar mío"- en palabras de Levinas- ante el rostro del Otro. Su planteo va más lejos aún, afirma que la

\footnotetext{
${ }^{5}$ La tematización que realiza Bello Reguera sobre la responsabilidad frente a los procesos migratorios parte de este eje (BELLO REGUERA 2010).

${ }^{6}$ Ponemos en discusión el falaz argumento del artículo de C. Sautereau que compara la subjetividad y vulnerabilidad en las filosofías de P. Ricoeur y E. Levinas, a partir de una lectura errónea e incompleta de la obra de Levinas, que concluye en que el contraste entre ellos se debe a que la filosofía de Levinas parte de la vulnerabilidad del otro, en oposición a Ricoeur, quien parte de la fragilidad del sujeto “cogito brise". (SAUTEREAU 2013, pp. 8-24).
} 
condición humana recién se produce al asumir la responsabilidad por el otro ser humano. "...La humanidad del hombre, la subjetividad, es una responsabilidad por los otros, una vulnerabilidad extrema" (LEVINAS 2001, p. 130).

Bajo la luz de esta inversión operada por la filosofía levinasiana podemos apreciar que el derecho, la justicia y el Estado -en cuanto órdenes normativos fundados por la razón- son secundarios y derivados de un nivel sensiblecorporal anterior, puesto que se fundan en una "pasividad originaria" del sujeto, en su "sensibilidad carnal" expuesta a la demanda del Otro, en su vulnerabilidad, en su donación y responsabilidad ante el mandato del rostro del Otro que lo obliga a su pesar. Afirma Levinas: “...la Razón, a la que se le atribuye la virtud de detener la violencia para desembocar en el orden de la paz, supone el desinterés, la pasividad o la paciencia" (LeviNAs 1987, p. 61), que son propias de la sensibilidad, la vulnerabilidad y la carnalidad.

Con anterioridad a la actuación de la razón, se encuentra ya anudada en la "sensibilidad" del sujeto una "responsabilidad irrecusable e inexcusable" para con el otro y con el "tercero" -el otro del Otro- donde se perfila la justicia y la paz como órdenes derivados de esta constitución subjetiva de la sensibilidad. Podríamos denominar a esto con el concepto de "solidaridad" que tanto uso y aceptación tiene hoy en la ciudadanía global.

Filosóficamente el autor ha dado así cabida argumentativa a la cuestión bíblica de la compasión y la misericordia. ${ }^{7}$ En su planteo la justicia está sometida a la "Bondad originaria" que resplandece en el rostro del Otro, que hace que cada sujeto sea único e irremplazable al elegirlo como responsable del prójimo. "La bondad da a la subjetividad su significación irreductible" (LEVINAS 1987, p. 64). La lógica de la justicia queda, de este modo, subordinada a la lógica de la solidaridad, en la que halla su legitimación, derivando esta última de un fundamento anterior a la arbitrariedad de la libertad, a la voluntad de poder, al reconocimiento simétrico de la conciencia y/o a la actuación de la razón. La vulnerabilidad del sujeto como "carne y sangre expuesta al otro" es el fundamento de la solidaridad y la justicia. "El rostro del prójimo significa para mí una responsabilidad irrecusable que antecede a todo consentimiento libre, a todo pacto, a todo contrato" (Id., p. 150).

\footnotetext{
${ }^{7}$ Los estudiosos y comentaristas concuerdan en reconocer la impronta mesiánica, profética y bíblica del giro ético y político que acomete Levinas. (CIARAMELLI 1991, pp. 83-105; DusSEL 2007, pp. 39-48; DuSSEL 2004, pp. 271-293; CHALIER 2007, pp. 13-34).
} 


\section{LA "VULNERABILIDAD" COMO SENSIBILIDAD CARNAL DEL SUJETO}

Para analizar e interpretar el concepto de "vulnerabilidad" en la filosofía de Levinas nos centraremos en su obra madura, ${ }^{8}$ particularmente en su texto principal en que desarrolla explícitamente el concepto: De otro modo que ser o más allá de la esencia, analizando su alcance y su potencialidad para fundar las lógicas de la solidaridad y la justicia frente a los procesos urbanos de vulnerabilidad creciente.

Emmanuel Levinas (1906 - 1995), filósofo judío lituano - francés, primer comentador de Husserl en Francia e introductor de la fenomenología en el ámbito francés de la década del '30, es sin duda uno de los filósofos europeos más originales del siglo XX y quizás uno de los más influyentes en la filosofía latinoamericana contemporánea por su concepción ética sobre la alteridad (DusSEL 1998; SCANNONE 1990). En este sentido coincidimos con F. Herrero Hernández cuando afirma que: "El gran mérito de Levinas es haber sacado del olvido al Otro, olvido al que la filosofía occidental nos había acostumbrado al privilegiar el interés del ser caracterizado por el "conatus in suo esse perseverand?" (Spinoza)” (HERRERo HERNÁNDEZ 2000, p. 272).

Levinas objeta el concepto de totalidad que domina la filosofía occidental que ha sostenido una libertad absoluta del individuo sin dejar resquicios para la primacía de los derechos del Otro afectada desde los orígenes históricos por "la alergia universal de la primera infancia de los filósofos" (LEVINAS 1972, 49). Con su original noción de subjetividad ética Levinas socava la base del sistema filosófico de la totalidad, cimiento de los totalitarismos políticos de Occidente, que ha investido a la libertad como un poder tiránico de la mismidad frente a toda alteridad, pudiendo excluirla y hasta eliminarla. ${ }^{9}$ En la totalidad histórica y objetiva del mundo, propia de una filosofía de la identidad y del absoluto,

\footnotetext{
${ }^{8}$ En la obra de Levinas se suele distinguir dos períodos con profundas continuidades y algunas rupturas: la obra juvenil, constituida por sus publicaciones de las décadas del '30 y del '40, y la obra de la madurez en la que publica las dos obras principales que recogen muchas de las intuiciones del anterior período: Totalidad e infinito. Ensayos para pensar la exterioridad (1961) y De otro modo que ser o más allá de la esencia (1974). (CRITCHLEY 2004, pp. 315-329; PALACIO 2008).

${ }^{9}$ En una famosa entrevista filosófica, Levinas expresa: “...Mi crítica de la totalidad surgió (...) después de una experiencia política que nosotros aún no hemos olvidado.” (LEVINAS 1991, p. 67).
} 
Levinas señala una rasgadura infinita: "la subjetividad ética". ${ }^{10} \mathrm{La}$ subjetividad como "hospitalidad" que recibe al Otro; situación en la que el yo se halla en una relación asimétrica con el rostro del otro y en la que siempre queda la sensación de inadecuación y exceso. Levinas se aproxima fenomenológicamente a la subjetividad a la que describe una y otra vez como: sensibilidad, vulnerabilidad, pasividad, sustitución, rehén, obsesión y traumatismo, en fin, responsabilidad inmemorial y anárquica por el otro/a.

La categoría de "vulnerabilidad" aparece en la obra madura de Emmanuel Levinas: el primer desarrollo se presenta en Humanismo del otro hombre (1972) que luego se profundiza de un modo más exhaustivo y complejo en De otro modo que ser o más allá de la esencia (1974). En esta obra, la vulnerabilidad es presentada como sensibilidad corporal de la subjetividad anterior a la conciencia, proximidad y contacto con el otro, pasividad originaria, por la cual alguien puede ser afectado y transformado en un "sujeto ético" por el mandato del rostro del otro, de quien debe responder de su hambre y desnudez, de su indigencia y clamor, convirtiéndose en un "elegido" para dar respuesta. De aquí la articulación que hace el filósofo entre los conceptos de "vulnerabilidad", "sensibilidad", "contacto", "proximidad", "pasividad originaria" con los de "obligación irrecusable", "obsesión", "traumatismo", "rehén".

Con el concepto de vulnerabilidad el autor desarrolla una cuestión clave en su obra al colocar la sensibilidad como fundamento de la ética, produciendo un notable "giro ético" respecto a sus antecesores filosóficos, sus maestros Husserl y Heidegger, y con la tradición filosófica de Occidente. En efecto, Levinas plantea una moral no-intelectualista cuyo origen y basamento es la vulnerabilidad ofrecida, la subjetividad de un sujeto definida por la sensibilidad corporal y no por la conciencia o la razón o la deliberación racional de la libertad (CHALIER 2002). Nos dice Levinas: "El sujeto, pues, no se describe a partir de la intencionalidad propia de la actividad representativa, de la objetivación, de la libertad y de la voluntad, sino que se describe a partir de la pasividad del tiempo" (LEVINAS 1987, p. 108).

Ya desde sus primeras obras juveniles De la existencia al existente (1947) y El tiempo y el otro (1948) el autor atisba una relación con la alteridad del Otro originaria y anterior a la constitución del ego trascendental husserliano y a

\footnotetext{
${ }^{10}$ Sobre la cuestión de la subjetividad en Levinas, puede consultarse: (PALACIO 2007, 115-123;
} MÉNDEZ 1994, 97-123; PONZIO 1996). 
cualquier comprensión consciente o donación de sentido. Con la evolución de su pensamiento esta intuición será profundizada y formulada como "relación ética" originada en el sujeto por la "afectación en la sensibilidad" que le produce la irrupción del rostro desnudo del Otro; relación ética anudada por la proximidad y el contacto sensible carnal frente a la demanda del Otro. La "revelación del otro", que irrumpe en la mismidad del sujeto, provoca una radical inversión de la intencionalidad del conocimiento objetivo puesto que acontece en una franja de no-conciencia intencional, en el contacto de la sensibilidad, y se produce en la proximidad del otro al recibirlo. De esta "sensibilidad afectada por el rostro del otro" es de donde brota la responsabilidad como anudamiento del otro-en-el-mismo (LEVINAS 1987). La relación con el otro, con el prójimo, se cumple en el Decir, esto es en "la responsabilidad para con este prójimo" donde "decir significa responder del otro" (Id., p. 99).

La primacía en la ética levinasiana la tiene la afectación corporal, de la carne, provocada por la proximidad y el contacto de la alteridad, de lo extraño o exterior al sí mismo, de lo otro que irrumpe desde afuera, y consecuentemente constituye pasivamente un sujeto ético que debe responder del otro antes que tenga conciencia reflexiva de ello (TUDELA 2002, p. 115). Desde esta perspectiva, la ética levinasiana ha logrado zafar del destino ontológico y del régimen de la totalidad que tanto escozor ha provocado a quien ha sido testigo del odio exterminador de Auschwitz, derivado -a su juicio- de una filosofía del ser, de la mismidad y de la totalidad, producida desde sus albores como "alergia universal de la primera infancia de los filósofos" (LEVINAS 1972, p. 49). ${ }^{11}$

El sujeto es para Levinas sensibilidad por cuanto está abierto al otro, es "significación" o "exposición al otro" anterior a un acto de la consciencia o de la representación. La sensibilidad para Levinas es la carne expuesta, abierta, entendiéndola como aproximación al otro, contacto, proximidad, Decir. Ya en las primeras páginas de De otro modo que ser Levinas vincula estos tres términos: "subjetividad", "sensibilidad" y "vulnerabilidad". Podemos afirmar que esta obra es la esforzada respuesta filosófica a la pregunta formulada al inicio de la obra: “...Cabe preguntar si la subjetividad como significación, como el-uno-

11 Allí dice: "El itinerario de la filosofía sigue siendo el de Ulises cuya aventura en el mundo sólo ha sido un retorno a su isla natal -una complacencia del Mismo, un desconocimiento del Otro" (LEVINAS 1972, p. 49). 
para- el-otro no remonta a la vulnerabilidad del yo, a la sensibilidad incomunicable y no-conceptualizable" (LEVINAS 1987, p. 59). Esta obra se presenta así como el intento de decir aquello que es no comunicable ni conceptualizable, que se halla en un tiempo inmemorial para la conciencia y, por lo tanto, absolutamente fuera del registro ontológico y representacional del lenguaje. Por este motivo su primer capítulo estará dedicado a señalar la anfibología del lenguaje, Decir y Dicho, a fin de argumentar sobre el lenguaje o Decir entendido como "relación ética de responsabilidad" con la alteridad. Varios autores han visto en esta teorización sobre el lenguaje un descomunal intento de dar cuenta a la crítica de J. Derrida a los resabios ontológicos del lenguaje de su primera gran obra Totalidad e infinito (PINTOR Ramos 1994; Herrero HERNÁNDEZ 2000).

En oposición al sujeto fuerte de la filosofía de la conciencia, Levinas opone un sujeto fisurado, herido, despojado de su etnocentrismo y de su egoísmo; sujeto partido en el núcleo de su identidad por la alteridad del Otro: "Esta ruptura de la identidad... es la propia subjetividad del sujeto o su sujeción a todo, esto es, su susceptibilidad, su vulnerabilidad, su sensibilidad" (LeVINAS 1987, p. 59). La vulnerabilidad es la "fisión del la identidad del yo" por una demanda y una responsabilidad, una "intriga", anterior a la conciencia reflexiva. A partir de este concepto de vulnerabilidad el autor intenta explicar cómo es que el clamor del otro, de su rostro desnudo y hambriento, puede perforar la coraza interesada e indiferente del yo y quedar abierto a responderle: a dar una respuesta irrecusable, obligado con una responsabilidad tal que lo convierte en "rehén del otro", como un "obsesión" que lo persigue día y noche, para donarse y sustituirse por el otro. Esta elección es lo que confiere la unicidad al sujeto: es irremplazable en el sentir de la responsabilidad por el otro (Id., pp. $170 \mathrm{y} \mathrm{ss})$.

La vulnerabilidad del sujeto está dada por su sensibilidad, "exposición al ultraje y a la herida: una pasividad más pasiva que toda paciencia" (LEVINAS 1987, p. 59). La subjetividad del sujeto entendida como "substitución del otro, expiación" (Id., p. 60). Por esta pasividad radical el sujeto es responsable del otro con anterioridad a la elección de su libertad. Es donación, signo, Decir, "despojo", "sacrificio sin reservas", "un sacrificio de rehén designado que no es elegido como rehén, sino posiblemente elegido por el Bien, con una elección involuntaria que no es asumida por el elegido" (Ibid.) Sobre estas bases puede pensarse la solidaridad como donación, en ese movimiento involuntario, anterior a la libertad, pura sensibilidad, despojo, sustitución de sí por el otro. 
La primacía del Otro sobre el yo implica una responsabilidad ética, pero además significa que la alteridad es constitutiva de la subjetividad en un momento anterior al saber o a la intencionalidad por cuanto el sujeto la ha recibido en la sensibilidad con anterioridad a la conciencia representacional. "La intencionalidad es hospitalidad, dice, pues, literalmente Levinas", afirma Derrida (DERRIDA 1998, p. 71).

En el arco de su pensamiento tendido entre sus dos obras principales, Totalidad e infinito (1961) y De otro modo que ser o más allá de la esencia (1974), vemos a Levinas profundizar y exacerbar esta idea del recibimiento u hospitalidad anterior a la conciencia. De la tematización del sujeto como "hospitalidad" de Totalidad e infinito, en que Levinas afirma "El sujeto es un anfitrión" (LEVINAS 1977, p. 303), su pensamiento inicia un movimiento que concluye en la radicalización de la formulación que expresa de De otro modo que ser o más allá de la esencia, la que conservando el concepto de hospitalidad se extrema en la afirmación "El sujeto es rehén" (LEVINAS 1987, p. 180).

Más que hablar de conciencia ética, en Levinas debe hablarse de subjetividad ética; noción que co-implica la pasividad y la responsabilidad, antes que actividad y libertad. "La subjetividad está estructurada como otro-enel-mismo" (LEVINAS 1987, p. 71) de un modo diferente a la conciencia de sí; es pura sensibilidad abierta en la proximidad. Se trata de una "sensibilidad ética": el Otro inquieta al Mismo, lo saca de su indiferencia y autocomplacencia de sí, y le imprime en la pasividad de su subjetividad una obligación de responsabilidad anterior a la conciencia y a la tematización.

Por su parte, esta "alteración" del yo dada por la responsabilidad anudada en la sensibilidad del sujeto es asimismo el origen de la conciencia de sí y del diálogo, de la tematización y de la justicia (LEVINAS 1987, p. 72). El Decir es anterior a lo Dicho: el uno-para-el-otro de la subjetividad anterior a lo que pueda saber o tematizar o representar sobre el otro y lo otro. De un plumazo invierte la centralidad que la tradición filosófica ha otorgado a la metáfora óptica de la razón y del ser que desde Platón hasta Heidegger dominan en el pensamiento occidental. Dice magistralmente Levinas: "La visión del ser y el ser remiten a un sujeto que se ha levantado más temprano que el ser y el conocimiento,... en un tiempo inmemorial que ninguna reminiscencia podrá recuperar como a priori" (Id., p. 73).

¿Qué quiere señalar Levinas con el Decir en su planteo ético al vincularlo con la sensibilidad de la carne expuesta? "Se trata de una significación referida al otro en la proximidad que decide sobre cualquier otra relación, que se puede 
pensar en tanto que responsabilidad para con el otro y se podría llamar humanidad, subjetividad o si mismo" (LEVINAS 1987, p. 97). El Decir como "intriga que no se reduce a la fenomenología" (Ibid.) ... "está al margen de la ontología" (Id., p. 98).

La proximidad es el "uno para el otro", sensibilidad como receptividad, afección corporal, exposición al otro, "donación". "Pasividad del ser para el otro que sólo es posible bajo las formas de la donación del propio pan que yo como" (LEVINAS 1987, p. 130). El sentido ético que Levinas otorga a la sensibilidad distingue su planteo del de sus predecesores filosóficos que han explicado la sensibilidad como mera receptividad (TudeLA 2002, p. 130). Para Levinas la sensibilidad no es mera recepción de cualquier estímulo sino que es "ser afectado inmediatamente por el otro humano", pasividad pura, "no-iniciativa de la sensibilidad" (LEVINAS 1987, p. 133).

Ser vulnerable es "estar expuesto", "haber-sido-ofrecido" (LEVINAS 1987, p. 133), experiencia sensible y encarnada del cuerpo donde se teje la "intriga ética", el lazo de responsabilidad irrecusable e irrevocable con el Otro: "yo estoy anudado a los otros antes de estarlo a mi cuerpo" (Id., p. 135). Levinas enfatiza que es en la "materialidad del cuerpo", en la sensibilidad o subjetividad, donde acontece este recibimiento o anudamiento ético del unopara-el-otro: su propia identidad de sujeto queda definida por esta significación anterior al presente de su conciencia y de la su iniciativa. Nos habla de un sujeto encarnado, que "tiene hambre y que come, entrañas en una piel y, por ello, susceptible de dar el pan de su boca o de dar su piel" (Id., p. 136).

La subjetividad así constituida por el otro apunta en el fondo a una "sustitución ética". "La subjetividad en su ser deshace la esencia substituyéndose por el otro" (LEVINAS 1987, p. 58). La subjetividad ética es el otro-en-el-mismo que desgarra la esencia identitaria y "des-inter-esa"12 al sujeto en la excelencia del uno-para-el-otro En las páginas finales de De otro modo que ser o más allá de la esencia, el autor concluye: "Este libro interpreta al sujeto como rehén y la subjetividad del sujeto como substitución que rompe con la esencia del ser" (Id., p. 265).

Con su particular estilo de escritura oscura y difícil, Levinas construye un texto que va profundizando iterativamente los conceptos para decir aquello

12 El des-inter-esse o "desinteresamiento de la esencia” (LEVINAs 1987, p. 265) es un término con el que el autor juega para oponer la subjetividad ética al conatus essendi o interés en permanecer en el ser. 
inefable puesto que ocurre en un "tiempo inmemorial y anárquico", que es inconceptualizable y que se escapa del registro ontológico del lenguaje. Cuando explica cómo funciona la afección en la sensibilidad utiliza la metáfora de la "maternidad": "el llevar por excelencia" (LEVINAs 1987, p. 134), gestar al otro en el mismo, "gemido de las entrañas" (Ibid.), arrancarse de sí mismo. Afirma: "En la maternidad significa la responsabilidad para con los otros, llegando hasta la substitución de esos otros y hasta sufrir tanto del efecto de la substitución como del perseguir, incluso allí donde se abisma el perseguidor" (Ibid.). La maternidad es el sentido último de la vulnerabilidad: es para-el-otro (Id., p. 175). La subjetividad es así un cuestionamiento constante a todo para-sí porque es un "otro dentro de lo mismo" (Id., p. 179).

De la alteridad del Otro sólo se tiene una pasiva "experiencia originaria" por la proximidad de su "rostro" (visage) que afecta y trastoca al sujeto, provocándole un dolor inevitable que se conmueve por la indefensión y vulnerabilidad propias del rostro; dolor que se expresa como responsabilidad y un hacerse cargo del rostro revelado. Catherine Chalier describe este encuentro con el rostro como un acontecimiento que sobrecoge al sujeto, provocándole un daño "que se asemeja al dolor de saber que este rostro está amenazado por la violencia y la muerte... aviva el sentido de la responsabilidad infinita del yo para con el otro" (CHALIER 1993, p. 80).

Este rostro deja su huella en la pasiva sensibilidad del sujeto antes de que él lo elija, como un clamor que lo individualiza -lo hace único- y le exige hacerse responsable y responder a su vulnerabilidad radical. "El rostro está expuesto, amenazado, como invitándonos a un acto de violencia. Al mismo tiempo, el rostro es lo que nos prohibe matar" (LEVINAS 1991, p. 72).

En suma, el giro radical del planteamiento de Levinas respecto a otros planteos éticos tradicionales se halla en su concepción de que la fuente y el basamento de la ética no es la comprensión del sufrimiento del otro -que es ya una modalidad de asimilar y poseer de la ontología- sino que es la afectación sensible y corporal en la propia subjetividad que queda ahora anudada por la responsabilidad del otro. En la proximidad de la vulnerabilidad o sensibilidad de la carne expuesta (vulnerabilidad del sujeto) el Otro irrumpe como rostro vulnerable y desnudo (vulnerabilidad de la alteridad), exige y clama por una responsabilidad, una respuesta irrecusable y que nos convierte en seres únicos, "elegidos". "La sensibilidad es la exposición al otro (...) una no-iniciativa que es más antigua que todo presente... (...) haber-sido-ofrecido-sin-reserva (...) vulnerabilidad" (LEVINAS 1987, p. 133). 


\section{LA VULNERABILIDAD FUNDANDO LA SOLIDARIDAD Y LA JUSTICIA}

Admitimos que en lo expuesto en el apartado anterior nuestra redacción ha sido doblegada por el encanto y la estructuración propia de la escritura levinasiana, plena de metáforas y alusiones, a tal punto que sólo hemos podido comentarlo citándolo textualmente, casi repitiéndolo sin poder escaparnos del hechizo de sus palabras, hecho que pareciera ocurrirle a numerosos comentaristas suyos y que Derrida lo advirtiera con agudeza tempranamente (DERRIDA 1989).

A partir de las lecturas levinasianas, asumiendo su concepción de la vulnerabilidad como "don y pura gratuitad involuntaria de sí al otro", estamos en condiciones de establecer la vulnerabilidad de la subjetividad humana como fundamento y origen de la "lógica de la solidaridad" porque sólo un ser de carne y hueso, un cuerpo animado y sensible, un ser vulnerable, puede ofrecerse y donarse como significación para el otro. La subjetividad es expresión de sí al otro, don gratuito del mismo al otro, desinteresado, en una relación no-recíproca o asimétrica; subjetividad que, en su pasividad originaria o en su vulnerabilidad intrínseca, está ligada al Bien.

La subjetividad es para Levinas "vulnerabilidad que responde"; que se hace responsable del Otro; respuesta sensible y carnal al otro, a su hambre y desnudez, a su vulnerabilidad, a su necesidad. Vulnerabilidad respondiendo de la vulnerabilidad. Subjetividad responsable que responde antes que la libertad y la conciencia realicen sus actividades. De este modo, el propio Levinas está indicando que la condición de toda solidaridad posible está dada porque "el sujeto es rehén": es quien soporta pasivamente la llamada del Otro que lo hace único e individualiza; quien no tiene alternativa entre la actividad o la pasividad; aquel que su identidad se resume en "expiación por el otro", involuntaria y anterior a la iniciativa de la voluntad. Nos dice: "el si mismo es bondad o está bajo la exigencia de un abandono de todo tener, de todo lo suyo y de todo para sí, hasta llegar a la sustitución" (LEVINAS 1987, p. 188).

Con su estilo, Levinas está diciéndonos que el yo es solidario con el otro antes de haberlo elegido. Dice el autor: "El prójimo me concierne antes de toda asunción, antes de todo compromiso consentido o rechazado. Estoy unido a él que, sin embargo, es el primer venido sin anunciarse, sin emparejamiento, antes de cualquier relación contratada" (LEVINAS 1987, p. 148).

Empero, también, desde el planteo levinasiano del "tercero", el otro del 
otro, podemos comprender la vulnerabilidad como fundamento de la "lógica de la justicia"; que se halla a nivel del discurso y de la razón, ambos niveles y esferas que adquieren sentido en la proximidad sensible de la vulnerabilidad: en la responsabilidad irrecusable que me obliga. "El tercero es otro distinto que el prójimo -dice Levinas-, pero es también otro prójimo, es también un prójimo del Otro y no simplemente su semejante" (LEVINAS 1987, p. 236).

El fundamento de la obligación jurídica del estado y de la ley racional no se halla en la Razón ni en la Libertad delegada -no se funda en el estado de guerra o de naturaleza de Hobbes- sino que se enraíza en la vulnerabilidad, es decir en la sensibilidad de la subjetividad, donde la responsabilidad por los otros ha constituido una intriga anárquica e inmemorial que obsesiona y obliga antes que toda conciencia y razón.

Con el tercero nace la cuestión de la justicia como cuestión de conciencia. "¿Qué deberé hacer con justicia?” (LEVINAS 1987, p. 236) se pregunta Levinas, rehabilitando así la inevitable esfera normativa de la existencia, imperfecta en su afán de expresar la radicalidad de la obligación ética frente a la alteridad absoluta del otro.

Las instituciones de la justicia, necesarias por cierto, son secundarias y derivadas del mandato original del rostro y del anudamiento inmemorial acontecido en la sensibilidad vulnerable del sujeto. Aquellas responden a la necesidad de la comprensión y de dar inteligibilidad a las acciones entre los hombres; a la necesidad de la intencionalidad y del intelecto que aspiran a tematizar y normar en reciprocidad. Se hace así necesaria "una copresencia sobre un pie de igualdad como ante una corte de justicia" (LEVINAS 1987, p. 236). Si en la relación ética de la solidaridad con el Otro hay "diacronía y asimetría", en esta esfera normativa de la justicia positiva, en cambio, es necesaria la sincronía, la reunión, la medida, la reciprocidad. Lo que, en última instancia, remite como a su fundamento a la responsabilidad irrecusable ante el Otro, a la subjetividad ética que, ya hemos visto, es Bondad. Levinas afirma: "Dentro de la proximidad del otro, me obsesionan todos los otros del otro y la obsesión clama ya justicia, reclama medida y sabe; es conciencia" (Id., p. 237).

En este sentido la solidaridad sería anterior y superior a la justicia por cuanto acontece en un tiempo inmemorial en la sensibilidad, en la carnalidad del cuerpo expuesto, en la significación pre-originaria del lenguaje, del Decir, de la exposición. Allí estaría el "anudamiento ético originario e inmemorial", la "intriga de responsabilidad" (LEVINAS 1987, p. 48) que se produce en la subjetividad antes que la conciencia reflexiva y la libertad realicen sus actos. La 
solidaridad como obligación de dar respuesta al otro, "donación del propio pan que yo como" (Id., p. 130), de "sufrir por él otro" (Id., p. 179), de soportarlo como el cuerpo materno lleva al otro y se ofrece por él (Id., pp. 133-135).

En cierto modo, Levinas nos está diciendo que antes que por la razón, estrategia, cálculo y astucia, debemos dejarnos llevar por el impulso ético de la emoción y la afección de la propia vulnerabilidad que nos provoca el rostro desnudo del otro; acontecimiento que siempre es anterior y pre-originario a la conciencia reflexiva y al lenguaje en su nivel de Dicho y registro ontológico. Allí, en la emoción sensible de la vulnerabilidad se produce el "anudamiento ético" del uno-para-el-otro. Claro que este fundamento será la condición de posibilidad de comprometernos posteriormente o de no hacerlo, propiamente condición de posibilidad de la libertad, donde se halla el inicio de la justicia para remediar el proceso de exclusión y de vulnerabilidad progresivo del otro propios de la lógica del egoísmo de la mismidad. Dice el autor: "Toda mi intimidad queda investida para-con-el-otro-a-mi-pesar" (LEVINAS 1987, p. 56).

A partir de aquí podemos pensar una "lógica de la justicia" que instituya leyes y garantice la protección a los más vulnerables de la sociedad, pero cuya cualidad de "justa" no le adviene porque sea legal sino porque se apoya en un "anudamiento ético" anterior y pre-originario de la subjetividad -a modo de "psiquismo en tanto que cuerpo maternal" (LEVINAS 1987, p. 124)- como cimiento del que brota la pura gratuidad de la solidaridad que se hace cargo sensible y vulnerablemente de la vulnerabilidad, desventaja, riesgo o amenaza que ronda a la vida del otro. La justicia es un momento posterior y necesario para equilibrar los intereses conflictivos de los sujetos egoístas que delegan racionalmente por tanto en el Estado la preservación de la paz, la retribución conforme a las acciones de cada uno, y la protección del tercero, a fin de que limitar y regular la arbitrariedad de la libertad que seducida por "el poder, por esencia asesino del otro" (LEVINAS 1977, p. 71), puede desarreglarse por la fuerza centrípeta y egológica del Mismo.

Desde este planteo levinasiano podemos pensar los procesos de inclusión como afincados en la lógica de la solidaridad y en la lógica de la justicia, legitimando las acciones solidarias (ayudas, colaboración, subsidiariedad, donación) y también acciones de justicia (petición en el espacio público por el tercero, revisión de la labor de las instituciones, contralor en el cumplimiento de las leyes y acciones positivas por las minorías y grupos desfavorecidos históricamente), cuyas sendas justificación y fundamentación residen en la "vulnerabilidad" de la propia subjetividad, en el don y la responsabilidad 
irrecusables del propio yo (ipseidad) de cada uno.

Esto implica una inversión en la procedencia de los conceptos clásicos de justicia y solidaridad, en los que a la justicia se la ubica como primaria y fundante de la acción ética ante los otros, y a la solidaridad se la concibe como originando aquellas acciones no-obligatorias -cual excedente de la medida de la norma-, quedando sujetas al puro arbitrio y decisión del individuo. Por el contrario, con el planteo de Levinas, primero se halla la solidaridad como obligación ética de responsabilidad por el otro porque "mi subjetividad vulnerable está constituida por una fisión del otro", ya que soy el "Otro-en-elMismo" (LEVINAS 1987, p. 72), ante cuyo rostro respondo de su ruego y su mandato de "No matarás" (LeVINAS 1991, p. 75). ${ }^{13}$ En segunda instancia está la justicia como ordenamiento normativo, como garantía legal, obligación positiva imprescindible para preservar precisamente la desviación de la arbitraria libertad y su sometimiento a la voluntad de poder, que puede hacer ó́dos sordos al clamor de la miseria y la desnudez del otro o del tercero dejándolo morir o que puede eliminarlo porque se contrapone a sus intereses, tal como la historia ha dado suficientes muestras.-

Marta Palacio

Universidad Nacional de Córdoba

martaipalacio@gmail.com

\section{BIBLIOGRAFÍA}

ARENDT, H. (2006): Los orígenes del totalitarismo, Madrid: Alianza.

Bello Reguera, G. (1994): "Levinas y la reconstrucción contemporánea de la racionalidad práctica", en G. GONZÁLEZ ARNAIZ, Ética y subjetividad. Lecturas de Emmanuel Levinas, Madrid: Editorial Complutense, pp. 149-182.

Bello ReguerA, G. (2010): "Alteridad, vulnerabilidad migratoria y responsabilidad asimétrica", Dilemata, n 3, pp. 119-127.

Benjamín, W. (2007): Sobre el concepto de la historia. Tesis y fragmentos, Buenos Aires: Piedras de papel.

ButLer, J. (2006): Vida precaria. El poder del duelo y la violencia, Buenos Aires: Paidós.

CHALIER, C. (1993), Levinas. La utopia de lo bumano, Barcelona: Riopiedras.

CHALIER, C. (2002): Por una moral más allá del saber. Kant y Levinas, Madrid: Caparrós

13 Allí afirma: "El "No matarás" es la primera palabra del rostro. Ahora bien, es una orden... Sin embargo, al mismo tiempo, el rostro del otro está desprotegido: es el pobre por el que yo puedo todo y a quien todo debo." 
Editores.

Chalier, C. (2007): “Témoignage et Théologie”, Anatéllei n 18, pp. 13-34.

Ciaramelli, F. (1991): “Levinas's Ethical Discourse Between Individuation and Universality”, en R. BERNASCONI \& S. CRITCHLEY (eds.): Re-Reading Levinas, Indiana: Indiana University Press, pp. 83-105.

CRITCHLEY, S. (2004): "Emmanuel Levinas. Un inventario dispar", en M. BARroso RAmos y D. PÉREZ CHICO, Un libro de huellas. Aproximaciones al pensamiento de Emmanuel Levinas, Madrid: Trotta, 2004, pp. 315-329.

DERRIDA, J. (1989): "Violencia y metafísica", en La escritura y la diferencia, Barcelona: Anthropos.

DerridA, J. (1998): "Palabra de acogida", en Adiós a Emmanuel Levinas. Palabra de acogida, Madrid: Mínima Trotta.

DerridA, J., Roudinesco, E. (2003): Y mañana qué..., Buenos Aires: Fondo de cultura económica.

Diario "La Nación” el 4/12/13. URL= http:/ /www.lanacion.com.ar/1644444-robos-ysaqueos-en-cordoba-durante-un-acuartelamiento-policial. Consultado 6-7-2013.

Dussel, E. (2007): “El 'deseo metafísico' en Levinas como solidaridad”, en Anatéllei, $\mathrm{n}^{\circ} 18$, pp. 39-48.

Dussel, E. (2004): "Lo político en Levinas (hacia una filosofía política 'crítica')", en M. BArroso RAmos y D. PÉrez CHico (eds.): Un libro de huellas. Aproximaciones al pensamiento de Emmanuel Levinas, Madrid: Trotta, pp. 271-293.

Dussel, E. (1998): Ética de la liberación en la edad de la globalización y de la exclusión, Madrid-México: Trotta-UNAM-UAM.

ECKholt, M. (2013): "Poesie der Stadt- Wie sieht die neue Stad aus" - "Poesía de la ciudad” ¿Qué figura tendrá la ciudad del futuro?”, Anatéllei, n³0, pp.9-38.

HERRERO HERNÁNDEZ, F.J. (2000): “Alteridad e infinito: la substitución en Levinas”, Cuadernos Salmantinos de Filosofía, Vol. XXVII, pp. 243-277.

Informe Regional de Desarrollo Humano 2013-2014. Seguridad ciudadana con rostro bumano: diagnóstico y propuesta para América Latina, ONU, 2013. URL= http://www.latinamerica.undp.org/content/dam/rblac/img/IDH/IDHAL\%20Informe\%20completo.pdf. Consultado el 18-4-2013.

LEVINAS, E. (2000): De la existencia al existente, Madrid: Arena Libros. Título del original: De l'existence à l'existant (1947), Paris: Vrin, 1973. Traducción de Patricio Peñalver.

LEVINAS, E. (1991): Ética e infinito, Madrid: La balsa de la Medusa. Título original: Éthique et infini, Paris : Fayar et Radio-France, 1982. Traducción de Jesús María Ayuso Díez.

LEVINAS, E. (2001): Humanismo del otro hombre, México: Siglo veintiuno editores. Título original: Humanisme del l'autre homme, Montpellier: Fata morgana, 1972. Traducción de Daniel Guillot. 
LEVINAS, E. (1977): Totalidad e infinito, Salamanca: Sígueme. Título del original: Totalité et Infini, La Haya: Martinus Nijhoff, 1961. Traducción de Daniel Guillot.

LEVINAS, E. (1987): De otro modo que ser o más allá de la esencia, Salamanca: Sígueme. Título del original: Autrement qu'être ou au-delà de l'essence, The Hague: Martinus Nihjoff, 1974. Traducción de Antonio Pintor Ramos.

LEVINAS, E. (1993): El tiempo y el otro, Barcelona: Paidós. Título del original: Le Temps et l'Autre (1948), Montpellier: Fata Morgana, 1979. Traducción de José Luis Pardo.

PALACiO, M. (2008): La mujer y lo femenino en el pensamiento de Emmanuel Levinas. Un debate de género en torno a la alteridad femenina, Córdoba: Educc.

PALACIO, M. (2007): "Emmanuel Levinas: el sujeto destituido. La subjetividad constituida", Stromata, n 63, pp. 115-123.

PinTor RAMOs, A., "En la frontera de la fenomenología", en G. González Arnaiz, Ética y subjetividad. Lecturas de Emmanuel Levinas, Madrid: Editorial Complutense, 1994, pp. 13-64.

PONZIO, A. (1996): Sujet et Alterité sur Emmanuel Levinas, Paris: L'Harmattan, 1996.

SARAVÍ, G. (Ed.) (2006): De la pobreza a la exclusión. Continuidades y rupturas de la cuestión social en América Latina, Buenos Aires: Prometeo.

SAUTEREAU, C. (2013): "Subjectivité et vulnérabillité chez Ricœur et Levinas", Études Ricoeuriennes, $\mathrm{n}^{\circ} 2$, pp. 8-24.

SCANNONE, J.C. (1990): Nuevo punto de partida en la filosofia latinoamericana, Buenos Aires: Editorial Guadalupe.

SCANNONE, J.C. (2013): "Fundamentación de una universalidad justa y solidaria a partir de la filosofía cristiana latinoamericana", Stromata, n ${ }^{\circ}$, pp. 233-246.

TOURAine, A. (2006): Un nuevo paradigma, Buenos Aires: Paidós.

TUDELA, J.A. (2002): "El sentido de la vulnerabilidad humana. La proximidad sensible en E. Levinas", Anámnesis n 24, pp. 111-143. 